\title{
O EU E O OUTRO EM “O ESPELHO”, DE JOÃO GUIMARÃES ROSA
}

\section{ME AND THE OTHER IN "THE MIRROR" BY JOÃO GUIMARÃES ROSA}

\author{
Vera Lucia Rodella ABRIATA \\ UNIFRAN - Universidade de Franca
}

\begin{abstract}
RESUMO: Ignacio Assis Silva, em sua obra Figurativização e Metamorfose: o mito de Narciso (1995), reflete sobre a relação entre o mito de Narciso e a construção do sujeito em Jacques Lacan. Segundo o autor, Freud e Lacan leem o Narciso ovidiano não como lenda, tal qual o liam os gregos e os romanos, mas como mito: como figurativização da antropogênese do sujeito. Com base nas observações de Silva, estabelecemos uma leitura semiótica para o conto "O espelho" de João Guimarães Rosa, objetivando analisar como o enunciador constrói de forma mitopoética o ator protagonista do texto, lendo-o também como figurativização da antropogênese do sujeito em sua relação com o outro.
\end{abstract}

PALAVRAS-CHAVE: Semiótica Francesa; Ator; Mito; Antropogênese do Sujeito.

ABSTRACT: Ignacio Assis Silva, in Figurativização e Metamorfose : o mito de Narciso (1995), reflects about the relation between Narcissus myth and the construction of the subject in Jacques Lacan. According to the author, Freud and Lacan read the Ovidian Narcissus "no more as a legend (as it seemed to be for the Greek and Romans), but as a myth: as a figurativization of the anthropogenesis of the subject. Based on Silva's observation, we established a semiotics reading to the short story "The mirror", by João Guimarães Rosa, aiming at analysing how the enunciator constructs in a myth poetic way the protagonist actor of the text, reading him also as a figurativization of the anthropogenesis of the subject his relation with the other.

KEYWORDS: French Semiotics; Actor; Myth; Anthropogenesis of the Subject.

\section{A enunciação enunciada: a proposição de contrato com o narratário}

Na sequência inicial do texto rosiano "O Espelho", há a projeção de um narrador, no presente da enunciação, por meio de uma debreagem enunciativa, que dialoga com um narratário, propondo-lhe narrar sua experiência com espelhos. Nesse diálogo, o eu revela-se detentor de um conhecimento sobre espelhos que o aparta do restante dos homens, inclusive do narratário, cujos conhecimentos científicos sobre o assunto ele reconhece, mas faz questão de frisar que seu /saber/ é diferenciado, pois se associa ao transcendental:

- Se quer seguir-me, narro-lhe; não uma aventura, mas experiência a que me induziram alternadamente, série de raciocínios e intuições [...] O senhor, por exemplo, que sabe e estuda, suponho nem tenha ideia do que seja na verdade - um espelho? Demais, decerto, das noções da física com que se 
familiarizou, as leis da óptica. Reporto-me ao transcendente. (ROSA, 1977, p. 61).

O narrador se revela, portanto, um sujeito cognitivo, conjunto com um /saber/ secreto sobre espelhos e intenta manipular o narratário a /querer-fazer/, ou seja, entrar também em conjunção com esse objeto modal. Assim, inicialmente constrói uma imagem positiva a seu respeito - "o senhor que sabe e estuda" - para, em seguida, avaliar veridictoriamente esse /saber/ como precário, ilusório, pois estaria relacionado somente à ciência física e não à metafísica. Desse modo, objetiva manipulá-lo com a intenção de levá-lo a entrar em conjunção com o /saber/ secreto, de caráter transcendental, que afirma deter sobre o assunto, e que se propõe revelar-lhe por meio do contar.

O processo de transmissão do /saber/ do narrador para o narratário se realiza de forma gradual, por meio de um relato em que aquele entretece reflexões sobre o ator "espelho", questionando sua natureza:

O espelho, são muitos, captando-lhe as feições; todos refletem-lhe o rosto, e o senhor crê-se com aspecto próprio e praticamente imudado, do qual the dão imagem fiel. Mas - que espelho? Há-os "bons" e "maus", os que favorecem e os que detraem; e os que são apenas honestos, pois não. E onde situar o nível e o ponto dessa honestidade ou fidedignidade? Como é que o senhor, eu, os restantes próximos, somos, no visível? (ROSA, 197, p.61).

O narrador investe o ator "espelho" do papel actancial de um sujeito Destinador manipulador cujo fazer persuasivo seria o de tecer imagens acerca de um outro sujeito, o ser humano, aí figurativizado por "o senhor", "nós", "os restantes próximos".

$\mathrm{O}$ ator "espelho" é definido, por sua vez, por meio de figuras generalizantes e indefinidas como "muitos" e "todos". Logo o narrador mantém em estado de segredo, de mistério o conhecimento que detém sobre o assunto. No entanto propicia-nos estabelecer uma correlação metafórica entre o espelho e diversas outras figuras que se manifestam no texto, tais como "fotografias", "retratos", "lentes das máquinas", "dados iconográficos", "olhos". Elas corresponderiam a diferentes revestimentos figurativos para um mesmo papel actancial: o de um sujeito Destinador manipulador, cujo papel seria o de dotar o ser humano de uma competência ilusória - um /saber/ sobre seu ser que, por ser baseado em imagens, seria enganoso, da ordem do /parecer/, mas /não-ser/. Por conseguinte, o ser humano, na medida em que se deixasse manipular por imagens - aceitando aquelas que o favoreceriam ou aquelas que o detrairiam - estaria mergulhado numa ilusão cognitiva, sobremodalizado por um /crer: saber-ser/.

Enfatizando a isotopia figurativa relacionada à imagem ilusória, o questionamento do narrador no enunciado "como é que o senhor, eu, os restantes próximos somos, no visível?" recobre um dos temas implicitados no texto - o do autoconhecimento do ser humano que seria enganoso se baseado em imagens especulares, advindas do outro, seu espelho. figura dos "olhos":

Em outro momento do texto, com o mesmo objetivo, o narrador destaca a

E os próprios olhos, de cada um de nós, padecem viciação de origem, defeitos com que cresceram e a que se afizeram, mais e mais. [...] Os olhos, por enquanto, são a porta do engano; duvide deles, dos seus, não de mim. (ROSA, 1977, p. 62). 
Destaca-se aí, a máxima "Os olhos são a porta do engano", mediante a qual o narrador alude ao engano em que incorre o ser humano que se identifica com as imagens ilusórias. Assim, insinua que o ser humano, ao moldar-se a uma visão sua preestabelecida pelo outro, os muitos espelhos, estaria dotado de um autoconhecimento mentiroso, de uma imagem sua que seria da ordem do /parecer/, mas do /não-ser/, sem relação de correspondência, por conseguinte, com a "verdade".

Ao final do primeiro segmento, o narrador revela o temor que sempre o acometeu de enfrentar sua imagem no espelho - temor que o acompanhara desde a infância e o atribui à superstição do homem do interior com quem se identifica:

Sou do interior, o senhor também; na nossa terra, diz-se que nunca se deve olhar em espelho às horas mortas da noite, estando-se sozinho. Porque, neles, às vezes, em lugar de nossa imagem, assombra-nos alguma outra medonha visão. Sou, porém, positivo, um racional, piso o chão a pés e patas. Satisfazer-me com fantásticas não-explicações? - jamais. Que amedrontadora visão seria então aquela? Quem o Monstro? (ROSA, 1977, p. $63)$.

Recusando-se a crer no /saber/ da ordem do misticismo arcaico-popular sobre a natureza da imagem medonha fornecida pelo sujeito "espelho", o narrador declara não mais deixar-se manipular por ela. Entretanto, ao situar a incoatividade do estado tenso-disfórico de medo dos espelhos em sua infância, o narrador aponta para a influência inegável que recebeu da cultura mística do interior, espaço de onde proveio, influência que perdura até o presente.

$\mathrm{O}$ efeito passional de medo, relacionado à credulidade popular, por outro lado, teria impelido o "eu pretérito" a uma sobremodalização pelo /dever-saber/, levando-o a automanipular-se para entender a causa desse temor. Nesse sentido, outra figura do texto - "é a superstição fecundo ponto de partida para a pesquisa" - pode ser considerada uma catáfora que prenuncia, em nível de enunciação, a origem do programa narrativo por meio do qual o eu passou a se mobilizar, no pretérito, para a aquisição de um /saber/ sobre a natureza da "medonha visão" e, somente ao adquirir tal conhecimento, é que pôde julgar essas imagens detratoras "ilusórias", "fantásticas não explicações".

O narrador vai-se desvelando, por conseguinte, um ser constitutivamente heterogêneo, influenciado tanto pela cultura arcaico-popular, quanto pelo conhecimento da ordem da ciência.

A faceta culta do narrador manifesta-se constantemente no relato, como podemos verificar, se nos reportarmos, por exemplo, à referência ao mito de Narciso que ele já explicitara em: "Tirésias havia predito ao belo Narciso que ele viveria apenas enquanto a si mesmo não se visse ... Sim, são para se ter medo, os espelhos". (ROSA, 1977, p. 62).

Ao aludir às predições de Tirésias acerca do percurso de vida de Narciso, o narrador antecipa que tratará do tema do autoconhecimento do ser humano, fazendo alusão às implicações narcísicas a ele relacionadas.

Logo, ao levar o enunciatário a refletir sobre os temas de sua história pretérita, o narrador vai alongando a temporalidade da enunciação, o que ele explicita, por meio da utilização do metadiscurso. Convém notar, nesse sentido, a importância de sua alusão ao processo narrativo que se corporifica no enunciado "Alongo-me, porém. Contava-lhe...". Essa é a via que ele encontra para retardar a projeção do enunciado enunciado em que situa sua história pretérita, o que ocorre na segunda sequência do texto. 


\section{Metamorfoses do eu pretérito: a busca da "vera forma"}

Esta sequencia inicia-se por uma debreagem temporal enunciativa em que há a revelação do narrador acerca do temor que o acometeu um dia, ao se dar conta de sua alteridade, quando visualizou sua figura em dois espelhos:

Foi num lavatório de edifício público, por acaso. Eu era moço, comigo contente, vaidoso. Descuidado, avistei... Explico-lhe: dois espelhos - um de parede, o outro de porta lateral, aberta em ângulo propício - faziam jogo. E o que enxerguei, por instante, foi uma figura, perfil humano, desagradável ao derradeiro grau, repulsivo, senão hediondo. Deu-me náusea aquele homem, causava-me ódio e susto, eriçamento, espavor. E era - logo descobri... era eu, mesmo! [...]

Desde aí, comecei a procurar-me - ao eu por detrás do mim - à tona dos espelhos, em sua lisa, funda lâmina, em seu lume frio. (ROSA, 1977, p. 63).

A "náusea", o "ódio", o "susto", o "eriçamento", o "espavor" são figuras que manifestam os estados passionais de medo e de angústia do sujeito "eu", responsáveis pela instauração de uma crise interna em que ele se enredou, ao vislumbrar sua figura monstruosa no espelho.

Nota-se, a partir daí, a revelação do programa narrativo de base do eu, como actante do enunciado - o início de seu percurso em busca do objeto-valor "identidade" manifestado em e "Comecei a procurar-me - ao eu por detrás do mim". Inconformado com a cisão interna que ele não queria aceitar e entender (/não querer-ser/), o eu começa a realizar vários programas narrativos de uso, desejando libertar-se inicialmente dos aspectos que em si mesmo ele abominava e que a imagem no espelho refletia.

A um estado narcísico de vaidade e de conformidade anteriores com sua imagem sucedeu-se, pois, um estado de inconformismo do eu perante a figura do outro, o desconhecido com o qual ele abruptamente se defrontou e que ele não pôde aceitar.

Assis Silva (1995, p. 187, grifo do autor) observa que na fase do espelho da teoria lacaniana, o objetivo de Narciso de "identificar-se com a imagem cuja beleza o fascina e imobiliza realiza uma alienação do desejo num objeto que está signado por uma valorização que depende dos cânones estéticos que o Outro (im)põe".

Seria, pois, esse objetivo narcisista que teria levado o sujeito "eu" a buscar o "eu por detrás do mim" à tona dos espelhos, atrás da imagem perdida que o envaidecia. O espelho, por sua vez, representando o outro, teria a função de revelar ao sujeito que esse outro buscado seria um objeto faltante, evanescente, como afirma Silva (1985, p. 189).

Conforme Laplanche e Pontalis (1998, p. 177), é importante lembrar que a fase do espelho, na teoria lacaniana, relaciona-se à constituição do primeiro esboço do ego. Nessa fase, a criança percebe na imagem do semelhante ou na própria imagem especular, uma forma em que antecipa uma unidade corporal que objetivamente lhe falta, identificando-se com essa imagem. A fase do espelho é que faria surgir retroativamente a fantasia do corpo fragmentado. No tratamento psicanalítico, segundo os autores, "vê-se, por vezes, aparecer a angústia de fragmentação por perda da identificação narcísica, e vice-versa". Seria, portanto, essa perda de identificação narcísica que teria passado a ocorrer com o eu pretérito. 
Voltando à temporalidade da enunciação, o narrador refere-se novamente ao tema do autoconhecimento, da busca da identidade, que estaria, no entanto, legada ao fracasso, na medida em que regida por um modelo que se associa ao "ego ideal" 1 :

Quem se olha em espelho, o faz partindo de preconceito afetivo, de um mais ou menos falaz pressuposto: ninguém se acha na verdade feio: quando muito, em certos momentos, desgostamo-nos por provisoriamente discrepantes de um ideal estético já aceito. Sou claro? O que se busca, então, é verificar, acertar, trabalhar um modelo subjetivo preexistente; enfim, ampliar o ilusório, mediante sucessivas novas capas de ilusão. (ROSA, 1977, p. 64, grifo do autor).

Desse modo, o narrador vai levando o narratário a perceber os enganos em que se enredou o eu no pretérito em busca de sua "vera forma". Antecipa, assim, um /saber/ que ele demoraria muito tempo para adquirir: o saber sobre suas tentativas de resgatar a imagem narcísica que o envaidecia, relacionada ao "ego ideal". Nesse sentido, sobremodalizado pelo /querer-saber/, o sujeito "eu" apoiou-se inicialmente no Destinador manipulador "ciência" para a aquisição de sua "vera forma":

$\mathrm{Eu}$, porém, era um perquiridor imparcial, neutro absolutamente. O caçador do meu próprio aspecto formal, movido por curiosidade, quando não impessoal, desinteressada, para não dizer o urgir científico. Levei meses. Sim, instrutivos. (ROSA, 1977, p. 64).

O narrador, entretanto, já declarara que seria inútil buscar no outro as respostas para o autoconhecimento. Seria "ampliar o ilusório mediante sucessivas, novas capas de ilusão" (ROSA, 1977, p. 64), de acordo com sua avaliação veridictória.

Por outro lado, vale destacar a figura "eu era um perquiridor imparcial, neutro absolutamente", que, aliada à "do urgir científico", delineia o percurso figurativo de busca do autoconhecimento, por parte do eu. Esse percurso se associa, no nível narrativo do texto, às performances do sujeito "eu", que iniciou um lento e gradativo processo de busca da modalidade do /saber/ sobre seu ser por meio da observação e do enfrentamento de suas imagens que ele passou a perscrutar nos espelhos, objetivando entendê-las com base inicialmente no conhecimento científico:

Operava com toda sorte de astúcias: o rapidíssimo relance, os golpes de esguelha, a longa obliquidade apurada, as contra-surpresas, a finta de pálpebras, a tocaia com a luz de repente acesa, os ângulos variados incessantemente. Sobretudo uma inembotável paciência. Mirava-me, também, em marcados momentos - de ira, medo, orgulho abatido ou dilatado, extrema alegria ou tristeza. Sobreabriam-se-me enigmas. Se, por exemplo, em estado de ódio, o senhor enfrenta objetivamente a sua imagem, o ódio reflui e recrudesce, em tremendas multiplicações: e o senhor vê, então, que, de fato, só se odeia é a si mesmo. Olhos contra os olhos. Soubeo: os olhos da gente não têm fim. Só eles pairavam imutáveis no centro do

\footnotetext{
${ }^{1}$ Laplanche e Pontalis (1998, p. 139) afirmam que o ego ideal, na teoria lacaniana, corresponde a uma "formação essencialmente narcísica que tem sua origem na fase do espelho e que pertence ao registro do imaginário". $\mathrm{O}$ texto em que Freud introduz o termo, segundo os autores, situa na origem da formação das instâncias ideais da personalidade o processo de idealização pelo qual o indivíduo tem como objetivo a reconquista do estado de onipotência do narcisismo infantil.
} 
segredo. Se é que de mim não zombassem, para lá de uma máscara. Porque, o resto, o rosto, mudava permanentemente. (ROSA, 1977, p. 64).

Nota-se, entretanto, que o "aprender a não ver" do sujeito "eu" relacionou-se à paixão do medo que o acometeu e a sua incompetência para /poder-fazer/, ou seja, poder aceitar as componentes que herdara da natureza animal e, ao mesmo tempo, aprendera na sua relação com o outro.

O narrador relata que ele obtinha sucesso na empreitada de libertar-se da faceta que o abominava, e os sujeitos destinadores da competência - do /saber-fazer/- para tanto, foram, além dos postulados da ciência, os oriundos da religião e da filosofia, em cujos métodos ele também se apoiou:

Mas, era principalmente no modus de focar, na visão parcialmente alheada, que eu tinha de agilitar-me: olhar não-vendo. Sem ver o que em "meu" rosto, não passava de reliquat bestial. [...]

E digo-lhe que nessa operação fazia reais progressos. Pouco a pouco, no campo-de-vista do espelho, minha figura reproduzia-se-me lacunar, com atenuadas, quase apagadas de todo, aquelas partes excrescentes. Prossegui. Já aí, porém, decidindo-me a tratar simultaneamente as outras componentes, contingentes e ilusivas. Assim, o elemento hereditário - as parecenças com os pais e avós - que são também, nos nossos rostos, um lastro evolutivo residual. [...] E, em seguida, o que se deveria ao contágio das paixões, manifestadas ou latentes, o que ressaltava das desordenadas pressões psicológicas transitórias. E, ainda, o que, em nossas caras, materializa ideias e sugestões de outrem; e os efêmeros interesses, sem sequência nem antecedência, sem conexões nem fundura. (ROSA, 1977, p. 65, grifos do autor).

Assim, o eu mobilizou-se para uma sucessão de fazeres que o levaram a uma gradual desreferencialização física, e da figura monstruosa inicial que ele vislumbrara no jogo de espelhos, sua imagem foi se transformando até que ele se deparou com sua "figura lacunar". Essas metamorfoses podem ser associadas ao tema da desumanização, visto que aos poucos ele foi aprendendo a negar tudo que em seu perfil lembrava a referência ao animal e ao humano.

Nesse momento, novamente dominado pela paixão do medo, já que os fazeres que tinham como objetivo libertá-lo do outro lado de seu eu o levaram a adoecer, o sujeito "eu", manipulado por intimidação, resolveu abandonar por algum tempo o programa narrativo de anulação das "partes excrescentes", o que se torna perceptível no excerto:

À medida que trabalhava com maior mestria, no excluir, abstrair e abstrar, meu esquema perspectivo clivava-se, em forma meândrica, a modos de couve-flor ou bucho de boi, e em mosaicos, e francamente cavernoso, como uma esponja. E escurecia-se. Por aí, não obstante os cuidados com a saúde, comecei a sofrer dores de cabeça. Será que me acovardei, sem menos? [...]. De golpe abandonei a investigação. Deixei, por meses, de olhar-me em qualquer espelho. (ROSA, 1977, p. 66).

A decisão do sujeito "eu" de abandonar os experimentos com espelhos ocorre ao final da segunda sequência do texto, e o narrador, no presente da enunciação, manifesta a 
dúvida sobre o estado patêmico de medo, de covardia em que se encontrou naquele momento passado em relação a tais experimentos.

\section{A assunção do eu heterogêneo}

A terceira sequência abre-se com uma reflexão do narrador acerca do papel do tempo. Depois de meses em que desistira de perseguir a "vera forma", assustado com o despojamento gradual dos caracteres físicos, que fora se operando em sua figura, o eu, novamente sobremodalizado pelo /querer-saber/, voltou a olhar-se no espelho e deparou-se com a "total desfigura".

Essa transformação de estado, todavia, não foi uma performance por ele realizada, mas foi se processando à sua revelia, com o passar do tempo:

Mas com o comum correr cotidiano, a gente se aquieta, esquece-se de muito. O tempo, em longo trecho, é sempre tranquilo. E pode ser, não menos, que encoberta curiosidade me picasse. Um dia... Desculpe-me, não viso a efeitos de ficcionista, inflectindo de propósito, em agudo, as situações. Simplesmente lhe digo que me olhei num espelho e não me vi. Não vi nada. Só o campo, liso, às vácuas aberto como o sol, água limpíssima, à dispersão da luz, tapadamente tudo. Eu não tinha formas, rosto? Apalpei-me em muito. Mas, o invisto. $\mathrm{O}$ ficto. $\mathrm{O}$ sem evidência física. Eu era - o transparente contemplador?... [...]

Com que, então, durante aqueles meses de repouso, a faculdade, antes buscada, por si, em mim se exercitara! Para sempre? [...]

Tanto dito que, partindo para uma figura gradualmente simplificada, despojara-me ao termo, até à total desfigura. E a terrível conclusão: não haveria em mim uma existência central, pessoal, autônoma? Seria eu um... des-almado? (ROSA, 1977, p. 66).

Evidencia-se ainda, nesse excerto do texto, o início da aquisição da competência para o autoconhecimento por parte do eu - /saber-ser/ - que se relaciona a seu processo de conscientização sobre a vacuidade existencial do ser humano, quando este deixa de considerar a importância do outro na constituição de sua identidade.

Para Lacan (1986, p.197-198):

[...] é num movimento de báscula, de troca com o outro que o homem se apreende como corpo, forma vazia do corpo. Da mesma forma, tudo o que está nele no estado de puro desejo, desejo originário, inconstituído e confuso, o que se exprime no vagido da criança - é invertido no outro que ele aprenderá a reconhecê-lo. Aprenderá, porque não aprendeu ainda, enquanto não colocamos em jogo a comunicação. [...]

Antes que o desejo aprenda a se reconhecer [...] pelo símbolo, ele só é visto no outro.

$\mathrm{Na}$ origem, antes da linguagem o desejo só existe no plano da relação imaginária do estado especular, projetado, alienado no outro. A tensão que ele provoca é então desprovida de saída. Quer dizer, não tem outra saída [...] senão a destruição do outro.

Segundo o psicanalista francês (LACAN, 1986, p. 198), o desejo do sujeito só pode, nessa relação, confirmar-se através de uma concorrência, de uma rivalidade absoluta com o outro, quanto ao objeto para o qual tende: "E cada vez que nos aproximamos, num 
sujeito, dessa alienação primordial, se engendra a mais radical agressividade - o desejo de desaparecimento do outro enquanto suporte de desejo do sujeito".

Logo, o fazer a que se voltou o sujeito "eu" pode ser homologado a esse desejo de desaparecimento do outro. Todavia, ao eliminar o que adveio do outro, ele sofreu metamorfoses que o levaram da figura, que ele inicialmente percebera monstruosa no espelho, para a total desfigura.

\section{O eu: uma nebulosa}

$\mathrm{Na}$ última sequência do texto, ocorrem outras metamorfoses com o eu que também se relacionam ao processo de passagem do tempo:

- Pois foi que, mais tarde anos, ao fim de uma ocasião de sofrimentos grandes, de novo me defrontei - não rosto a rosto. O espelho mostrou-me. Ouça. Por um certo tempo, nada enxerguei. Só então, só depois: o tênue começo de um quanto como uma luz, que se nublava, aos poucos tentandose em débil cintilação, radiância. [...] Que luzinha, aquela, que de mim se emitia, para deter-se acolá, refletida, surpresa? [...]

Por aí, perdoe-me o detalhe, eu já amava - já aprendendo, isto seja, a conformidade e a alegria. E ... Sim, vi, a mim mesmo, de novo, meu rosto, um rosto; não este que o senhor razoavelmente me atribui. Mas o ainda-nemrosto-quase delineado, apenas - mal emergindo, qual uma flor pelágica, de nascimento abissal... E era não mais que: rostinho de menino, de menos-quemenino, só. Só. Será que o senhor nunca compreenderá? (ROSA, 1977, p. $68)$.

O término do sofrimento do eu, como se pode observar no excerto acima, deveu-se à aquisição de competência para amar e, em consequência, para /poder-fazer/: aceitar-se heterogêneo, o que se revela em "O espelho mostrou-me". Que espelho seria esse senão o outro, que ele pôde começar a aceitar e a amar?

Assim, a figura da "luzinha" que dele se emitiu pode ser considerada uma metáfora que o narrador utiliza para revestir essa descoberta do sujeito. Ela se relaciona a sua percepção, depois de muito sofrimento, de que começara, enfim, a reconhecer-se "homem humano" (ROSA, 1976, p. 460).

Portanto ao /saber/ ilusório, associado a uma autoimagem que o eu imaginara positiva, homogênea, predeterminada - e que se relacionava, pois, a seu "ego ideal" ${ }^{2}$ sobrepõe-se a incoatividade do processo de aquisição do /saber/ verdadeiro sobre sua radical heterogeneidade. Logo, ao procurar um "modelo subjetivo preexistente", o eu partiu da figura monstruosa que vislumbrara no espelho e, com seus programas narrativos relacionados a seu lado racional, chegou à total desfigura. Por outro lado, somente ao adquirir a competência para amar a si mesmo como sujeito extremamente heterogêneo e, portanto, para aceitar

\footnotetext{
${ }^{2}$ Laplanche e Pontalis (1998, p. 139, grifo nosso) observam que a expressão "ego ideal", segundo Lacan, pertence ao registro do imaginário e se distingue da expressão "ideal do ego", que corresponde "à instância da personalidade resultante da convergência do narcisismo (idealização do ego) e das identificações com os pais, com seus substitutos e com os ideais coletivos. Enquanto instância diferenciada, o ideal do ego constitui um modelo a que o indivíduo procura conformar-se".
} 
também os outros seres humanos em sua radical heterogeneidade, mistério e imperfeição é que o eu pôde ver-se novamente.

Nesse momento, outra metamorfose que sofreu o eu pretérito, e que se manifesta no texto pela figura do "rostinho de menino" que ele vislumbrou no espelho, corresponde ao início do processo de sua humanização.

É importante observar, de acordo com Lacan (1986, p. 198), que os sofrimentos com os quais se defrontou o eu se relacionaram a seu desejo de fazer desaparecer o outro, suporte de seu desejo. Mas o psicanalista francês afirma que, como o sujeito está imerso no mundo do símbolo, num "mundo de outros que falam", seu desejo é suscetível da mediação do reconhecimento. Convém aqui citar Lacan (1986, p.198) novamente, para apreendermos a relação que se estabelece entre suas reflexões e o momento em que o eu se reconhece outro e no outro:

[...] Inversamente, cada vez que, no fenômeno do outro, algo aparece que permite ao sujeito reprojetar, recompletar, nutrir, como diz Freud em algum lugar, a imagem do Ideal-Ich, cada vez que se refaz de maneira analógica a assunção jubilatória do estádio do espelho, cada vez que o sujeito é cativado por um de seus semelhantes, o desejo volta no sujeito. Mas volta verbalizado. (LACAN, 1986, p. 198, grifo do autor).

perfeição".

Nesse aspecto, é que, para Lacan (1986, p. 166), “o amor reabre a porta [...] à

É interessante enfatizar, ainda em relação ao excerto supracitado, a explicitação do tema da radical heterogeneidade do ser humano. O narrador dirige-se ao narratário, observando que ele, como sujeito da instância da enunciação, já era um outro, que começou a nascer, a construir-se, a perceber-se humano num momento pretérito, no momento em que pôde conformar-se com sua diversidade, enfim, com seu insondável mistério. No presente, por conseguinte, ele já se sabe outro. Daí a importância da menção que faz à imagem do menino no espelho, explicando ao narratário que ela não mais correspondia a sua imagem presente. Evidencia-se, portanto, que, de sua perspectiva, o autoconhecimento seria um objeto-valor evanescente ${ }^{3}$, a ser perseguido continuamente ao longo da travessia da vida e nunca se moldaria às imagens ideais, preconcebidas, oriundas unicamente de um /saber/ de ordem racional. Pelo contrário, tal conhecimento de nada lhe valeria se, paralelamente a ele, não houvesse a aquisição de outra competência construída interna, progressiva e continuamente ao longo do percurso existencial: a capacidade para amar-se e aceitar-se heterogêneo, contraditório e, a partir daí, /poder-fazer/, ou seja, amar e aceitar o outro como seu espelho igualmente heterogêneo.

Nesse sentido, vale ressaltar que, ao término do relato, o narrador volta-se para o narratário, dirigindo-lhe questionamentos sobre o mistério da personalidade humana, por meio de enunciados interrogativos com os quais finaliza os quatro últimos parágrafos do texto. Isso nos remete, enquanto enunciatários, ao início do texto. Ali o narrador se propusera narrar um /saber/ de caráter transcendental acerca da natureza dos espelhos. Afinal, pode-se concluir que esse /saber/ relaciona-se à conscientização do ser humano, acerca da radical

\footnotetext{
${ }^{3}$ Aplicando a teoria lacaniana da fase do espelho na análise que faz do mito de Narciso, Silva (1995, p. 195) observa, a partir das reflexões de Vallejo, que "O je - que menta e mente o sujeito - nega com sua ilusória unidade o lugar de uma cisão; funciona como mero suporte de uma carência. Assim, como nas aulas de anatomia se obtém, pela sobreposição de transparências, uma ilusória unidade do corpo humano, a sobreposição dos registros real, simbólico e imaginário produz esse efeito de integração que é a ilusória unidade do eu (je)”.
} 
heterogeneidade e mistério que constituiriam a essência de seu ser, enfim, de que o eu é constituído do outro, seu espelho. Explicita-se, dessa forma, ao enunciatário que a "vera forma", arduamente buscada pelo eu pretérito, ao longo de seu percurso existencial, permaneceria uma nebulosa ${ }^{4}$.

Convém mencionar aqui, conforme Lacan (1986, p. 164), que o transcendente relaciona-se à ligação simbólica entre os seres humanos:

O que é a ligação simbólica? É [...] que socialmente nós nos definimos por intermédio da lei. É da troca de símbolos que nós situamos uns em relação aos outros nossos diferentes eus [...].

Em outros termos, é a relação simbólica que define a posição do sujeito como aquele que vê. É a palavra, a função simbólica que define o maior ou menor grau de perfeição, de completude, de aproximação ao imaginário.

Dessa perspectiva, outro /saber/ secreto, de caráter transcendental, que o enunciador nos possibilitou desvendar no espelho linguístico de seu texto, relaciona-se à relação especular que estabelece no tex to com o mito.

Observa-se que o enunciador, em "O espelho", simula construir o mito, no sentido em que o entendem Freud e Lacan, ou seja, como figurativização da antropogênese do sujeito. Na verdade, porém, o ator "eu" é fruto da linguagem literária que, por sua vez, dialoga tanto com a narrativa de Ovídio ${ }^{5}$, quanto com o conceito de mito no sentido psicanalítico. Nesse sentido, por conseguinte, é que entendemos o texto rosiano como mitopoético.

É interessante ressaltar a observação de Lacan (1986, p. 164), quando reflete sobre a função simbólica da palavra, que imprime a ela um caráter transcendental. Para o psicanalista francês, seria essa a função responsável pelo maior grau de perfeição, de completude, de aproximação do imaginário a que poderíamos chegar. Podemos associá-la a uma tentativa de resposta a um questionamento do narrador, quando o eu pretérito se dá conta de que sua identidade se constituía da alteridade:

Então, o que se me fingia de um suposto eu, não era mais que, sobre a persistência do animal, um pouco de herança, de soltos instintos, energia passional estranha, um entrecruzar-se de influências, e tudo o mais que na impermanência se indefine? Diziam-me isso os raios luminosos e a face vazia no espelho - com rigorosa infidelidade. E seria assim com todos? Seríamos não muito mais que as crianças - o espírito do viver não passando de ímpetos espasmódicos, relampejados entre miragens: a esperança e a memória. (ROSA, 1977, p. 67, grifo do autor).

\footnotetext{
${ }^{4}$ Uma retroleitura do texto possibilita-nos observar que o narrador antecipara também esse /saber/ de forma cifrada ao narratário, quando, ao referir-se àquele que seria o programa narrativo de base do eu pretérito, utilizase do dêitico "essa" no enunciado "Sendo assim, necessitava eu de transverberar o embuço, a travisagem daquela máscara, a fito de devassar o núcleo dessa nebulosa - a minha vera forma". (ROSA, 1977, p. 64, grifo nosso). Ao aludir, no presente da enunciação, à sua "vera forma" como uma "nebulosa", ele antecipa ao narratário, mais uma vez, um /saber/ que o eu, como sujeito do enunciado, demoraria para adquirir.

5 Nota-se que o diálogo com a narrativa ovidiana se processa, no texto "O Espelho", por meio de uma relação polêmica, uma vez que o percurso do "eu" deste conto pode ser considerado um percurso narcísico às avessas.
} 
Vale notar o encurtamento da distância que se processa nesse excerto entre o "eu" e o "nós". À angústia do eu - que figurativiza o ser humano - frente à consciência da cisão originária, memória inscrita em nosso corpo, reagimos com a aspiração, a esperança de resgatar a completude, de acordo com a teoria psicanalítica que parece ressoar nas duas figuras em destaque.

De acordo com Lacan, caberia à palavra construir, com maior ou menor grau de perfeição, a ponte entre a esperança e a memória. A nosso ver, a palavra poética rosiana, na medida em que ressemantiza valores inscritos em discursos outros que partilhamos com nossa comunidade enunciativa, cumpre tal papel de modo radicalmente inovador.

\section{Referências bibliográficas}

LACAN, J. Os escritos técnicos de Freud. Rio de Janeiro: Jorge Zahar, 1986. (O Seminário, livro1).

LAPLANCHE, J. ; PONTALIS, J. B. Vocabulário de psicanálise. 7. ed. São Paulo: Martins Fontes, 1998.

ROSA, J. G. Grande sertão: veredas. 10 ed. Rio de Janeiro: José Olympio, 1976. . Primeiras estórias. 10 a ed. Rio de Janeiro: José Olympio, 1977.

SILVA, I. A. Figurativização e metamorfose: o mito de Narciso. São Paulo: UNESP, 1995. 